\title{
The efficacy of a brief, peer-led nutrition education intervention in increasing fruit and vegetable consumption: a wait-list, community-based randomised controlled trial
}

\author{
Colleen Glasson ${ }^{1, *}$, Kathy Chapman ${ }^{1}$, Kristi Gander ${ }^{1}$, Tamara Wilson ${ }^{1}$ and \\ Erica James ${ }^{2}$ \\ 'The Cancer Council NSW, PO Box 572, Kings Cross, NSW 1340, Australia: ${ }^{2}$ School of Medicine and Public \\ Health, University of Newcastle, Newcastle, NSW, Australia
}

Submitted 6 April 2011: Accepted 2 January 2012: First published online 8 February 2012

\begin{abstract}
Objective: The objective of the present research was to test the efficacy of Fruit \& Veg \$ense sessions in increasing fruit and vegetable consumption.

Design: A wait-list randomised controlled trial was conducted ( $n$ 292). Intervention participants attended a Fruit \& Veg \$ense session and received newsletters at weeks 2 and 5 after attending the session. All participants completed an FFQ and a questionnaire measuring knowledge, attitudes, barriers and stage of change for fruit and vegetable consumption at baseline and 6 weeks.

Setting: Hunter region of New South Wales, Australia.

Subjects: Two hundred and ninety-two parents with children of primary school age. Results: The intervention group significantly increased its mean consumption of fruit and vegetables by 0.62 servings compared with 0.11 in the control group (difference of $0.51, P=0.001$ ). Compared with the control group, there were significant increases in intervention participants' knowledge of daily recommended servings (for fruit and vegetables) and serving size (for vegetables), improvement in stage of change for vegetable consumption and a decrease in the number of perceived barriers to fruit and vegetable consumption.

Conclusions: Fruit \& Veg \$ense is efficacious in increasing fruit and vegetable consumption among parents of primary-school children. The study adds significantly to the limited evidence regarding fruit and vegetable interventions and the feasibility of engaging peer educators to deliver community education sessions. A broader implementation trial to test the effectiveness of Fruit \& Veg \$ense is recommended.
\end{abstract}

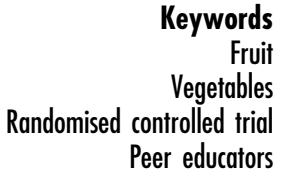

Peer educators
An adequate fruit and vegetable intake is protective against a number of chronic diseases including some cancers and $\mathrm{CHD}^{(1-4)}$, and can potentially achieve decreases in healthcare costs ${ }^{(5)}$. Significant health gains can be made from even small increases in fruit and vegetable intake. For example, increasing intakes of fruit and vegetables by just $50 \mathrm{~g} / \mathrm{d}$ (equivalent to two-thirds of a cup of cooked vegetables or a third of a piece of fruit) has been associated with a reduction in cancer risk of about $20 \%{ }^{(6)}$, while an increased consumption of fruit and vegetables from less than three to more than five servings daily is related to a $17 \%$ reduction in $\mathrm{CHD}^{(7)}$.

Nutrition surveys in Australia suggest that fruit and vegetable consumption is inadequate, with approximately $50 \%$ of the adult population meeting the fruit recommendation of two servings daily and only $10 \%$ meeting the vegetable recommendation of five servings daily ${ }^{(8,9)}$.

In Australia, the national Go for $2 \& 5^{\circledR}$ fruit and vegetable campaign has been conducted since 2005.
Media and social marketing aim to increase consumers' awareness of the benefits of fruit and vegetable consumption and knowledge of recommended intakes and serving sizes. The evaluation of the national campaign has shown a high level of awareness of the campaign and an increase in the knowledge of parents, particularly in the area of recommended consumption of vegetables ${ }^{(10)}$. However, the high cost and short-lived nature of media campaigns mean that more needs to be done at a community level to promote, prolong and extend the messages so that additional sustained behaviour change is achieved.

The Eat It To Beat It Program is a multi-strategy pilot intervention that was conducted in the Hunter region of Australia during 2008-2010. The Hunter region is in New South Wales, approximately $150 \mathrm{~km}$ north of Sydney. It includes the major regional centre of Newcastle with a population of approximately 540000 and a number of smaller outlying regional and rural communities. 
The Eat It To Beat It Program delivered a mix of community-based health promotion interventions and community engagement strategies to parents designed to complement and extend the effects of the social marketing strategies of the Go for $2 \& 5^{\circledR}$ fruit and vegetable campaign.

The target group was parents of children of primary school age responsible for food preparation within their household. There is ample evidence that encouraging parents to be positive role models by targeting parental intake and creating a supportive home environment through increased encouragement and availability of fruit and vegetables are positively associated with children's fruit and vegetable consumption ${ }^{(11)}$.

Nutrition education is one of a range of strategies that can be employed at a community level to achieve an increase in fruit and vegetable consumption. Nutrition education has been defined by Contento ${ }^{(12)}$ as:

any combination of educational strategies, accompanied by environmental supports, designed to facilitate voluntary adoption of food choices and other food and nutrition-related behaviours conducive to health and well-being; nutrition education is delivered through multiple venues and involves activities at the individual, community, and policy levels.

A brief peer-led nutrition education intervention was conducted as one of the strategies within the Eat It To Beat It Program. While there is some evidence to support the efficacy of nutrition education in increasing consumption of fruit and vegetables, there are very few studies that isolate and examine the efficacy of peer-led group education sessions with supplemental printed educational materials in general or low-income populations ${ }^{(13,14)}$.

Peer educators have been used by some programmes with success ${ }^{(15,16)}$. In Australia, programmes such as the Food Cent\$ Program ${ }^{(17)}$ and the North Coast Heart Health Program $^{(18)}$ have used peer educators to deliver their programmes. Peer education stems from the notion that 'natural helpers' within the social networks of a community can be engaged to increase the competence of that community to address health problems ${ }^{(19)}$. It is postulated that peer educators can be successful within their community because they may be more likely to identify with the issues, concerns and barriers to adopting the health behaviour, particularly in low-income groups, than those seen as 'experts' in the area ${ }^{(17)}$. Buller et al. ${ }^{(20)}$ suggest that peer educators

serve as informal opinion leaders who improve the quality of messages about health behaviour, tailor messages to the unique needs and culture of a social group and stimulate the classic diffusion of innovation process.

Henrikson et al. suggest that peer educators can be both an agent of change and a respondent to change, so that their participation in the delivery of the programme and their modelling of the desired behaviour may be effective in initiating behaviour within their community ${ }^{(18)}$. In addition, using trained peer educator volunteers to deliver education sessions within their own community may be a cost-effective method of achieving behaviour change $\mathrm{e}^{(17,18)}$.

The purpose of the present study was to determine the efficacy of a brief nutrition education strategy, delivered by peer educators, in increasing the fruit and vegetable consumption, knowledge, attitudes and skills of parents. The main goal of the brief intervention was to increase the consumption of fruit and vegetables in the target group. Secondary study goals included: a positive movement in stage of change for increasing fruit and vegetable consumption; an increase in positive attitudes towards fruit and vegetables; an increase in awareness of the benefits of fruit and vegetables, the recommended daily intake of fruit and vegetables and serving sizes; an improvement in perceived adequacy of intake and self-efficacy for providing fruit and vegetables for the family; a reduction in the stated barriers to change in fruit and vegetable consumption; and a change in the family's intake.

\section{Methodology}

\section{The intervention}

The Fruit \& Veg \$ense programme consisted of a $90 \mathrm{~min}$ education session. The session content included teaching the recommended intakes and serving sizes for fruit and vegetables and the amount of the food budget that should be spent on fruit and vegetables. The health benefits of fruit and vegetables for the family (particularly in relation to cancer) and the budgeting aspects of the sessions helped to enhance the participants' motivation to purchase and consume more fruit and vegetables. Recipe modification and strategies for including fruit and vegetables throughout the day helped to define an 'action' phase of how to make the changes ${ }^{(12)}$. The session was supported with printed educational materials including a cookbook featuring eleven recipes and was followed by a newsletter mailed to participants at weeks 2 and 5 after attending the session. The newsletters were designed to reinforce what was learnt at the session, to provide further educational information and to motivate participants to make the required changes in consumption. Research has shown that interventions are more successful when multiple contacts are made with participants ${ }^{(13)}$.

The theoretical underpinnings of the Fruit \& Veg \$ense strategy were based on a model proposed by Van Duyn et al. ${ }^{(21)}$. Those authors examined a number of theoretical models of behaviour such as Social Cognitive Theory ${ }^{(22)}$ and health promotion planning models such as the PRECEED-PROCEED model ${ }^{(23)}$ to conceptualise the factors that influence healthy eating. They postulated that focusing 
on the modifiable predisposing and enabling factors, such as knowledge and awareness, attitudes, self-efficacy, perceived barriers and threats and enhancing the social support and norms associated with eating fruit and vegetables, would lead to a progression along the stageof-change continuum ${ }^{(24,25)}$ resulting in an increase in fruit and vegetable consumption.

In order to provide social support and change norms associated with consumption of fruit and vegetables, the programme was implemented by peer educators. The session was based on adult learning principles ${ }^{(26)}$ and was interactive so that participants could share their experiences with the group and learn from each other. The peer educators were either community members with an interest in nutrition, or health, education or welfare workers with well-developed links to the community. Peer educators underwent a half-day training session and had to pass a competency test to enable them to conduct sessions.

Due to the large number of sessions to be delivered to achieve the sample size, a number of dietetics students from the local university were also trained to deliver the programme. One student was a parent and most students lived in the communities in which they led sessions. Therefore, by virtue of their knowledge of their community, their links to the community and the fact that many of them were on low incomes, they were likely to identify with the issues, concerns and barriers to adopting the health behaviour, particularly in low-income groups.

Project officers had the discretion to 'pass' any participating nutrition professionals without undertaking the competency assessment based on their previous experience/role. This occurred in only a few instances.

\section{Procedures}

The research design was a randomised controlled trial with a wait-list control. Ethics approval for the study was granted by the Cancer Council NSW's Ethics Committee in November 2007 (approval number 233). The trial commenced in April 2008 and concluded in October 2010. Trials registration: Australian New Zealand Clinical Trials Registry ACTRN12611000277943.

Recruitment of participants to the trial was from free-living community members using newspaper advertisements and other advertising, word of mouth and recruitment presentations, or through schools, sporting clubs, shopping centres and other community organisations. There were no incentives offered for participation, participants were not charged to attend the educational sessions and all resources were provided at no cost.

The individual was the unit of randomisation with randomisation on a 1:1 basis. A computer-generated list that randomly sequenced intervention and control places was generated. Participants were screened for inclusion using a pre-defined telephone script. Eligible participants were then posted written informed consent forms and were asked to complete the pre-programme surveys. Once participants returned their forms by mail, they were allocated to either the intervention group or the control group by adding them to the list of intervention and control places in order of receipt of the envelopes by mail. The allocation of participants to intervention and control groups was concealed from the peer educators implementing the sessions, from the data entry personnel and the participants. The trial continued until a sufficient sample size had been attained. Intervention participants attended the first session available after return of their forms, received follow-up newsletters at weeks 2 and 5 and completed their post-programme surveys at week 6 after attending their session. Control participants were enrolled with the expectation that they would be offered the intervention, but the delivery to the control group was delayed for a period of 6 weeks to allow them to complete their post-programme surveys (wait-list control). Participants were simply advised as to the availability of sessions and were not aware of their status in the trial.

\section{Participants}

Eligible participants included parents or carers of children of primary school age residing in the Hunter region of Australia who were not consuming the recommended daily intake of fruit and vegetables at the time of the trial. This was assessed by two short screening questions asking potential participants how many servings of fruit and vegetables they were eating each day. Participants had to be willing to undertake the complete Fruit \& Veg \$ense Program and intend to remain in the Hunter region for 6 months following their enrolment in the trial.

\section{Sample size}

The sample size was determined to be 150 per group as this would allow the detection of differences of 0.5 of a serving of fruit and vegetables ( 1 serving of fruit $=150 \mathrm{~g}$ and 1 serving of vegetables $=75 \mathrm{~g}$ ), assuming a standard deviation of 1.6 servings $^{(27)}$, with $95 \%$ significance and $80 \%$ power.

\section{Measures}

The primary outcome of fruit and vegetable consumption was measured using the Dietary Questionnaire for Epidemiological Studies (DQES) ${ }^{(28)}$. This FFQ has been validated to estimate food intake over the previous 12 months. Further validation of this FFQ has shown that it is suitable for estimation of dietary intakes where the intervention time was 6 weeks ${ }^{(29)}$. The participants were given clear instructions to recall their dietary habits over the previous 6 weeks of the trial.

The secondary goals were measured by a questionnaire designed and piloted by the research team. The thirtytwo-item questionnaire included questions on knowledge of recommended daily intakes, serving sizes for adults and benefits of fruit and vegetables, attitudes, perceived 
adequacy of intake, perceived self-efficacy for providing fruit and vegetables for the family, change in the family's intake, stage of change, barriers to fruit and vegetable intake and demographic information.

1. Age of respondents was initially collected in five discrete age-range categories. The three most common categories are reported.

2. Education was categorised as those with Year 12 or less, those with a trade or certificate (technical education) and those with university graduate or postgraduate qualifications.

3. Knowledge of recommended intake for fruit and vegetables was assessed by asking the respondents how many servings of fruit (or vegetables) they thought they should eat every day to maintain good health. The open-ended responses (the number of servings needed) were then categorised as either correct or incorrect.

4. Serving size knowledge was assessed by asking the respondents what they thought one serving of fruit (or vegetables) was equal to. Response choices were different cup measures ( $\frac{1}{2}$ cup', ' 1 cup', ' $1 \frac{1}{2}$ cups' or

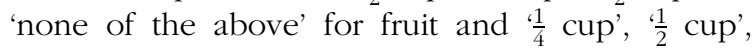
' 1 cup' or 'none of the above' for vegetables). The responses were then dichotomised as correct or incorrect.

5. Correct perception of fruit and vegetable intake was measured by asking the respondents if they thought the amount of fruit (or vegetables) they currently eat was 'too little', 'about right' or 'too much'. These categories were further collapsed to those who thought they ate 'too little' and those who thought they ate 'enough or too much'. This was then matched to their actual intake from the FFQ to determine if their perception of their intake was correct or incorrect.

6. Change to the family's fruit and vegetable intake was assessed by asking the respondents if in the last 6 weeks they had tried to increase or decrease the amount of fruit (or vegetables) their family eats. The options supplied were 'no', 'yes, increased' or 'yes, decreased'.

7. Perceived self-efficacy for providing fruit and vegetables for the family was measured by asking the respondents how sure they were that they could succeed in increasing the amount of fruit (or vegetables) their family eats, with responses directed by a Likert scale including 'very sure', 'sure', 'somewhat sure', 'unsure' and 'very unsure'. This was then re-categorised as 'sure' or 'unsure'.

8. A stage of change algorithm described and used in a previous study ${ }^{(25)}$ was used to assess stage of change separately for fruit and vegetables.

9. Barriers to fruit and vegetable intake were measured by asking respondents what prevents them from eating more fruit (or vegetables). Respondents could select one or more of seven responses.

10. Fruit and vegetable knowledge was assessed by asking the respondents if they agreed or disagreed with three statements relating to cancer, the cost of fruit and vegetables and frozen vegetables. These was then categorised as either correct or incorrect ('disagree' or 'don't know').

\section{Data analysis}

It was hypothesised that compared with the control group, participants who completed the Fruit \& Veg \$ense programme would change their family's intake and report increased fruit and vegetable consumption, increased knowledge of recommended intakes and serving sizes, improve their attitudes and perceived self-efficacy, move along the stage-of-change continuum for fruit and vegetable consumption and state fewer barriers to consumption. Intention-to-treat analysis was used with non-completers in the intervention and control groups assigned their baseline values.

Data were analysed using the SPSS statistical software package version 17 for Windows (SPSS Inc., Chicago, IL, USA). Continuous and categorical outcome variables were compared by $t$ tests and $\chi^{2}$ tests, respectively. To identify a difference between intervention and control groups at follow-up (post-test), logistic regression analysis was used, where the models were adjusted for baseline measures (pre-test) by including them as covariates. All results reported here were pre-specified. Results were considered statistically significant at the $P<0 \cdot 05$ level.

\section{Results}

\section{Recruitment and adberence to study protocols}

Eligible participants were recruited in two waves between the following time frames: April-October 2009 and April-October 2010 (Fig. 1). Two hundred and ninety-two participants (153 intervention and 139 control) were enrolled in the trial. Two hundred and twenty-nine participants (114 intervention and 115 control) attended the Fruit \& Veg \$ense sessions and completed both FFQ. The FFQ of two control participant questionnaires were not able to be scanned and were discarded. Two hundred and thirty-one participants (113 intervention and 118 control) completed both secondary questionnaires. There were no harms or unintended effects reported.

Demographic characteristics of the sample are shown in Table 1. There were no differences in initial combined fruit and vegetable intake or demographic characteristics between those for whom there were complete data and those who had incomplete data, except for education level. The group that completed both the pre- and postsurveys had a higher level of education $\left(\chi^{2}=9 \cdot 123\right.$, $P=0 \cdot 010)$. 


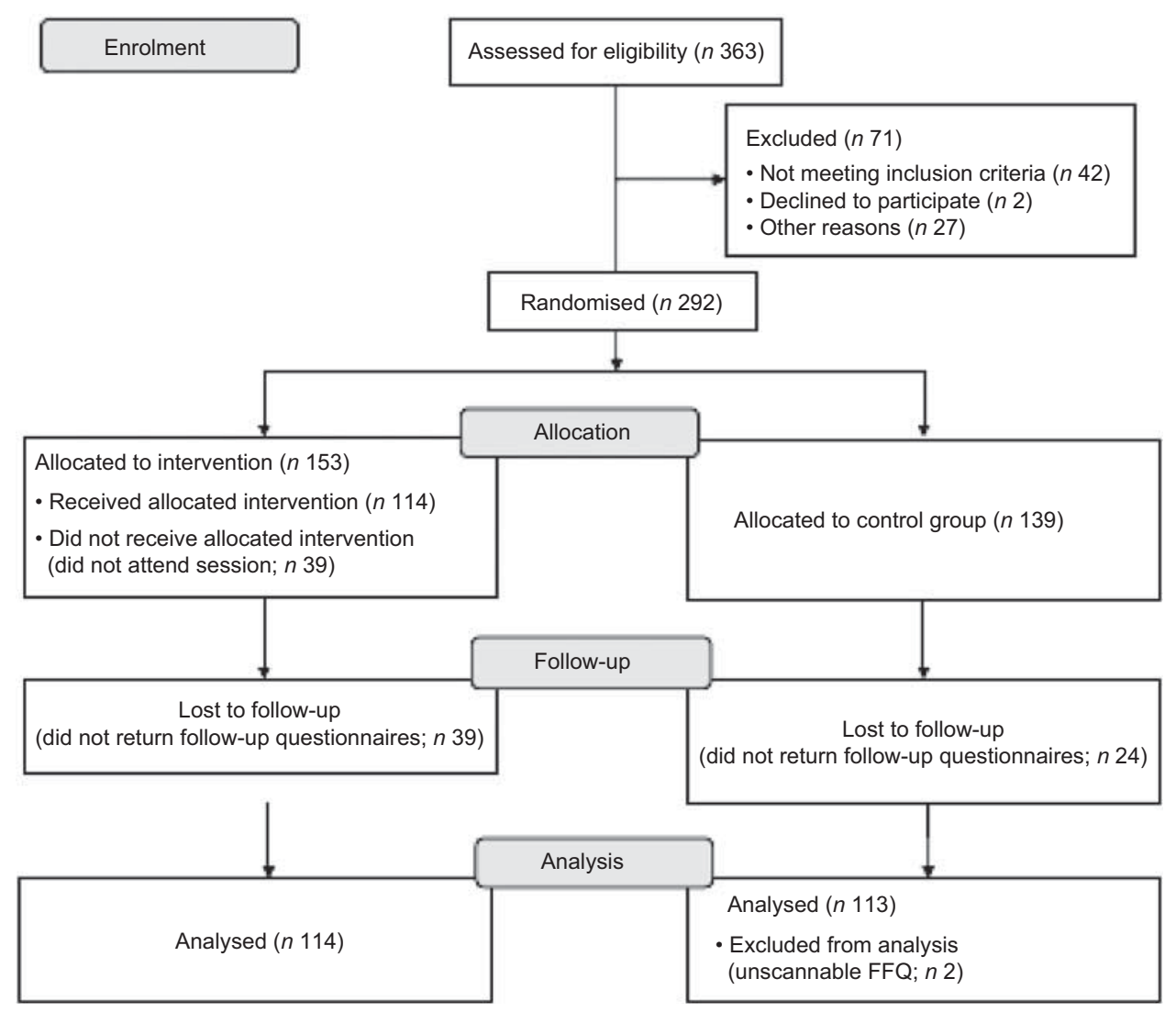

Fig. 1 Flowchart of participants in the study

\section{Changes in consumption}

Mean baseline consumption and changes post-intervention for total fruit and vegetables and fruit and vegetable servings individually are shown in Table 2 . There was a net difference in change of 0.51 servings for fruit and vegetables combined in intervention participants compared with controls $(P=0 \cdot 001)$. There was a net difference in change of 0.24 servings for fruit $(P=0.009)$ and 0.28 for vegetables in intervention participants compared with controls $(P=0 \cdot 010)$.

\section{Changes in knowledge, attitudes and self-efficacy}

Changes in knowledge, attitudes and self-efficacy are detailed in Table 3. Post-programme, intervention participants were more likely to be able to state the correct serving size for vegetables $(P=0.002)$ and the correct recommended servings for both fruit $(P=0.007)$ and vegetables $(P=0 \cdot 001)$, compared with control participants. They were also more likely to be able to state the approximate percentage of food budget* that should be allocated to fruit

* The proportion of the food budget that should be spent on fruit and vegetables was approximately $40 \%$. This approximation was determined by modelling a comprehensive weekly menu plan for a family of four (consisting of two adults over the age of 19 years and two children both of school age; one female aged over 12 years and one male aged under 12 years) that meets the minimum serving recommendations for all food groups as determined by the Australian Guide to Healthy Eating ${ }^{(30)}$ and costed using research on the cost of a healthy food basket conducted by the Cancer Council NSW ${ }^{(31)}$. and vegetables $(P=0 \cdot 000)$, more likely to recognise that eating enough fruit and vegetables decreases the risk of certain types of cancer $(P=0 \cdot 039)$, more likely to agree that vegetables are easy to prepare and serve for the family $(P=0.003)$ and that frozen vegetables are an acceptable alternative to fresh fruit and vegetables $(P=0 \cdot 005)$. Intervention participants were less likely to state that they find it difficult to buy fruit and vegetables for their family because of the cost $(P=0 \cdot 050)$. Intervention participants were more likely to have tried to change their family's vegetable consumption in the 6 weeks post-intervention $(P=0.004)$ and more likely to state that they were confident in succeeding in increasing the amount of vegetables their family eats $(P=0 \cdot 044)$ than control participants.

\section{Stage of change}

There was no difference in the proportion of people who increased their stage of change for fruit between intervention participants and control participants $(P=0 \cdot 961$; Table 4). There were significantly more intervention participants who increased their stage of change for vegetables compared with control participants $(P=0 \cdot 008$; Table 4).

\section{Barriers to consumption of fruit and vegetables}

After attending the education session, intervention participants were significantly less likely to claim 'habit' $(P=0 \cdot 013)$, 'too expensive' $(P=0 \cdot 000)$ and 'not enough 
Table 1 Demographic characteristics of the sample: parents with children of primary school age, Hunter region of New South Wales, Australia, 2009-2010

\begin{tabular}{|c|c|c|}
\hline \multirow[b]{2}{*}{ Characteristic } & \multicolumn{2}{|c|}{ Total sample ( $n$ 292) } \\
\hline & $n$ & $\%^{*}$ \\
\hline \multicolumn{3}{|l|}{ Age (years) } \\
\hline $25-34$ & 55 & 19 \\
\hline $35-44$ & 183 & 63 \\
\hline $45-54$ & 53 & 18 \\
\hline \multicolumn{3}{|l|}{ Gender } \\
\hline Female & 278 & 95 \\
\hline Male & 14 & 5 \\
\hline \multicolumn{3}{|l|}{ Household type } \\
\hline Single parent & 30 & 10 \\
\hline Other & 262 & 90 \\
\hline \multicolumn{3}{|l|}{ Number of children living at home } \\
\hline 1 & 42 & 14 \\
\hline 2 & 165 & 56 \\
\hline 3 & 67 & 23 \\
\hline 4 or more & 18 & 6 \\
\hline \multicolumn{3}{|l|}{ Marital status } \\
\hline Married/de facto & 263 & 90 \\
\hline Other & 29 & 10 \\
\hline \multicolumn{3}{|l|}{ Highest level of education } \\
\hline Year 12 or less & 67 & 23 \\
\hline Technical education & 115 & 39 \\
\hline $\begin{array}{l}\text { University graduate or postgraduate } \\
\text { qualifications }\end{array}$ & 109 & 37 \\
\hline \multicolumn{3}{|l|}{ Current employment } \\
\hline Full time & 45 & 15 \\
\hline Part time & 155 & 53 \\
\hline Home duties & 68 & 23 \\
\hline Other & 24 & 8 \\
\hline \multicolumn{3}{|l|}{ Annual household income } \\
\hline Less than $\$ A U 40000$ & 35 & 14 \\
\hline$\$ A U 40000-80000$ & 90 & 30 \\
\hline More than \$AU 80000 & 149 & 51 \\
\hline Other & 16 & 6 \\
\hline \multicolumn{3}{|l|}{ Main language spoken at home } \\
\hline English & 289 & 99 \\
\hline Other & 3 & 1 \\
\hline
\end{tabular}

*The denominator changes due to missing values.

interesting and tasty ways to serve fruit' $(P=0 \cdot 020)$ as barriers to fruit consumption compared with control participants (Table 5). After attending the education session, intervention participants were also significantly less likely to claim 'too expensive' $(P=0 \cdot 013)$, 'don't know how to prepare vegetables' $(P=0 \cdot 003)$ and 'not enough interesting and tasty ways to serve vegetables' $(P=0 \cdot 000)$ as barriers to vegetable consumption compared with control participants (Table 5). When the total number of barriers were summed and the difference in barriers computed (post-intervention pre-intervention), the intervention participants had significantly decreased the number of barriers stated for both fruit consumption $(P=0 \cdot 001)$ and vegetable consumption $(P=0 \cdot 000)$ compared with the control group.

\section{Discussion}

Our findings of a net increase in consumption of fruit and vegetables of 0.51 servings at 6 -week follow-up suggest

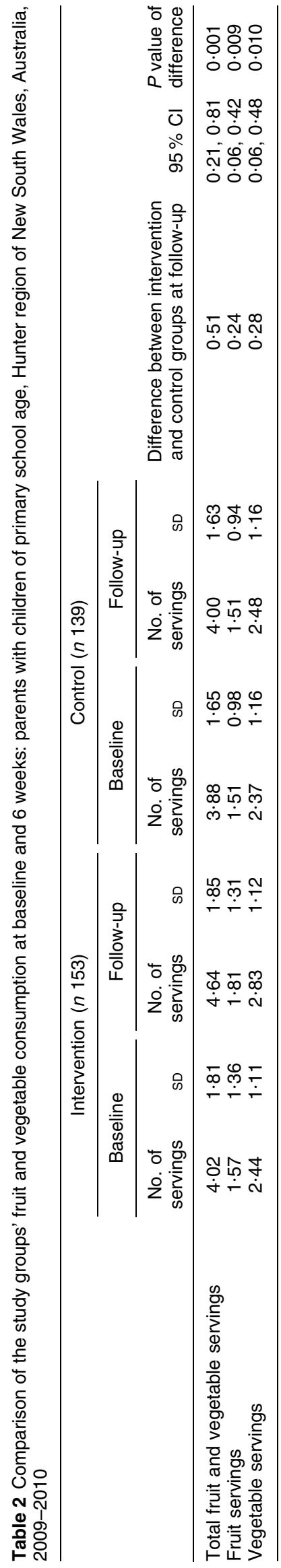


Table 3 Knowledge, attitudes, perceptions and self-efficacy outcomes at 6-week follow-up: parents with children of primary school age, Hunter region of New South Wales, Australia, 2009-2010

\begin{tabular}{|c|c|c|c|}
\hline & OR & $95 \% \mathrm{Cl}$ & $P$ value \\
\hline Correct knowledge of fruit serving size & $1 \cdot 79$ & $0 \cdot 99,2 \cdot 80$ & 0.052 \\
\hline Correct knowledge of vegetable serving size & $2 \cdot 43$ & $1 \cdot 40,4 \cdot 22$ & 0.002 \\
\hline Correct knowledge of recommended servings of fruit per day & $2 \cdot 43$ & $1 \cdot 28,4 \cdot 65$ & 0.007 \\
\hline Correct knowledge of recommended servings of vegetables per day & $2 \cdot 80$ & $1 \cdot 54,5 \cdot 10$ & 0.001 \\
\hline Correct perception of current fruit intake & $0 \cdot 74$ & $0.42,1.29$ & 0.287 \\
\hline Correct perception of current vegetable intake & $0 \cdot 88$ & $0.52,1.48$ & 0.623 \\
\hline Tried to change family's fruit intake in last 6 weeks & $1 \cdot 63$ & $0 \cdot 94,2 \cdot 84$ & 0.079 \\
\hline Tried to change family's vegetable intake in last 6 weeks & $2 \cdot 40$ & $1 \cdot 32,4 \cdot 38$ & 0.004 \\
\hline Confidence in increasing the amount of fruit the family eats & $2 \cdot 00$ & $0 \cdot 62,6 \cdot 45$ & $0 \cdot 246$ \\
\hline Confidence in increasing the amount of vegetables the family eats & $3 \cdot 69$ & $1 \cdot 04,13 \cdot 16$ & $0 \cdot 044$ \\
\hline $\begin{array}{l}\text { Knowledge of approximate percentage of food budget that should be allocated } \\
\text { to fruit and vegetables }\end{array}$ & $3 \cdot 37$ & $1 \cdot 96,5 \cdot 78$ & $0 \cdot 000$ \\
\hline Eating enough fruit and vegetables decreases risk of certain types of cancer & $15 \cdot 78$ & $1 \cdot 12,90 \cdot 90$ & 0.039 \\
\hline Belief that vegetables are easy to prepare and serve to the family & $2 \cdot 78$ & $1 \cdot 42,5 \cdot 46$ & 0.003 \\
\hline Difficulty in buying fruit and vegetables for the family because of the cost & 0.52 & $0 \cdot 27,1 \cdot 00$ & 0.050 \\
\hline Belief that frozen vegetables are an acceptable alternative to fresh fruit and vegetables & $3 \cdot 93$ & $1 \cdot 39,6 \cdot 17$ & 0.005 \\
\hline
\end{tabular}

Table 4 Fruit and vegetable stage of change before and after the intervention: parents with children of primary school age, Hunter region of New South Wales, Australia, 2009-2010

\begin{tabular}{|c|c|c|c|c|c|c|c|c|}
\hline & \multicolumn{4}{|c|}{ Fruit stage of change pre-programme } & \multicolumn{4}{|c|}{ Vegetable stage of change pre-programme } \\
\hline & \multicolumn{2}{|c|}{ Intervention ( $n$ 151) } & \multicolumn{2}{|c|}{ Control ( $n$ 135) } & \multicolumn{2}{|c|}{ Intervention ( $n$ 151) } & \multicolumn{2}{|c|}{ Control ( $n$ 136) } \\
\hline & $n$ & $\%^{*}$ & $n$ & $\% *$ & $n$ & $\% *$ & $n$ & $\%^{*}$ \\
\hline Pre-contemplation & 11 & 7 & 27 & 20 & 42 & 28 & 39 & 29 \\
\hline Contemplation & 11 & 7 & 4 & 3 & 11 & 7 & 9 & 7 \\
\hline Preparation & 79 & 52 & 68 & 50 & 90 & 60 & 85 & 62 \\
\hline Action/maintenance & 50 & 33 & 36 & 27 & 8 & 5 & 3 & 2 \\
\hline
\end{tabular}

Fruit stage of change post-programme

\begin{tabular}{|c|c|c|c|c|c|c|c|c|}
\hline & \multirow{2}{*}{\multicolumn{2}{|c|}{ Intervention (n 152) }} & \multirow{2}{*}{\multicolumn{2}{|c|}{ Control (n 136) }} & \multirow{2}{*}{\multicolumn{2}{|c|}{ Intervention ( $n$ 153) }} & & \\
\hline & & & & & & & \multicolumn{2}{|c|}{ Control $(n$ 139) } \\
\hline & $n$ & $\%^{*}$ & $n$ & $\%^{*}$ & $n$ & $\%^{*}$ & $n$ & \%* \\
\hline Pre-contemplation & 18 & 12 & 19 & 14 & 33 & 22 & 45 & 32 \\
\hline Contemplation & 4 & 3 & 11 & 8 & 8 & 5 & 9 & 6 \\
\hline Preparation & 69 & 45 & 70 & 52 & 104 & 68 & 83 & 60 \\
\hline Action/maintenance & 61 & 40 & 36 & 26 & 8 & 5 & 2 & 1 \\
\hline
\end{tabular}

*Percentage of the total in each trial group; the denominator changes due to missing values.

Table 5 Self-reported barriers to fruit and vegetable consumption following the intervention: parents with children of primary school age, Hunter region of New South Wales, Australia, 2009-2010

\begin{tabular}{|c|c|c|c|c|c|c|}
\hline \multirow[b]{2}{*}{ Barrier to consumption } & \multicolumn{3}{|c|}{ Fruit } & \multicolumn{3}{|c|}{ Vegetables } \\
\hline & OR & $95 \% \mathrm{Cl}$ & $P$ value & OR & $95 \% \mathrm{Cl}$ & $P$ value \\
\hline Habit & $2 \cdot 07$ & $1 \cdot 16,3 \cdot 68$ & 0.013 & $1 \cdot 61$ & $0 \cdot 91,2 \cdot 86$ & $0 \cdot 105$ \\
\hline Too expensive & $7 \cdot 52$ & $2 \cdot 71,20 \cdot 83$ & $0 \cdot 000$ & $4 \cdot 39$ & $1 \cdot 37,14 \cdot 08$ & $0 \cdot 013$ \\
\hline Already eat enough in my diet & 0.52 & $0.26,1.05$ & 0.068 & $1 \cdot 22$ & $0.57,2 \cdot 58$ & $0 \cdot 604$ \\
\hline Don't know how to prepare & $3 \cdot 86$ & $0 \cdot 71,20 \cdot 83$ & $0 \cdot 117$ & $4 \cdot 42$ & $1 \cdot 66,52 \cdot 63$ & 0.003 \\
\hline Not enough interesting and tasty ways to serve & $2 \cdot 35$ & $1 \cdot 15,4 \cdot 81$ & $0 \cdot 020$ & $3 \cdot 86$ & $2 \cdot 00,7 \cdot 52$ & 0.000 \\
\hline Differing family tastes & $1 \cdot 30$ & $0 \cdot 70,2 \cdot 40$ & $0 \cdot 404$ & $1 \cdot 28$ & $0 \cdot 73,2 \cdot 25$ & 0.379 \\
\hline $\begin{array}{l}\text { Limited accessibility (i.e. once weekly shoppers, } \\
\text { poor availability/quality) }\end{array}$ & $1 \cdot 54$ & $0 \cdot 74,3 \cdot 19$ & $0 \cdot 247$ & $1 \cdot 83$ & $0 \cdot 87,3 \cdot 85$ & $0 \cdot 112$ \\
\hline
\end{tabular}

that the Fruit \& Veg \$ense programme is efficacious at increasing fruit and vegetable consumption by parents of primary-school children in the short term.
Two systematic reviews of dietary interventions to increase fruit and vegetable consumption have reported evidence of the effectiveness of fruit and vegetable 
education interventions, with consistent positive effects seen in studies involving face-to-face education ${ }^{(13,14)}$.

One review of nutrition education interventions for mothers of young children in their own homes or in small neighbourhood groups identified a number of studies that achieved statistically significant increases of fruit and vegetable consumption from 0.43 to 1.6 servings $^{(13)}$. For example, one intervention using group nutrition education sessions led by peer educators reported an increase of 0.43 servings of fruit and vegetables ${ }^{(32)}$. Another study reported a mean change from baseline of $0 \cdot 40$ servings of fruit and vegetables measured at 8 months with an intervention led by peer educators that included five interactive workshops and follow-up newsletters ${ }^{(33)}$.

Another review found consistent positive effects in programmes involving face-to-face education including group education $^{(14)}$. Haire-Joshue et al. demonstrated an increase at 6 months of 0.53 servings of fruit and vegetables among African-American parents as a result of an intervention with a mix of personal home visits, group meetings and newsletters ${ }^{(34)}$. A church-based intervention using an ecological framework of strategies targeting the individual, social network and community level, including group education sessions and follow-up support materials, resulted in the intervention group consuming 0.85 servings of fruit and vegetables more daily than the control group at the end of the trial ${ }^{(15)}$. Langenburg et al. reported an increased mean consumption by 0.54 servings compared with $0 \cdot 13$ in the control group for an intervention involving nutrition sessions delivered by peer educators, printed materials and individualised direct mail as part of the Special Supplemental Nutrition Program for Women, Infants, and Children (WIC) ${ }^{(16)}$.

The current study is a brief intervention using fewer resources than the studies discussed above and it has a correspondingly shorter follow-up time. Under these circumstances a net increase of 0.51 servings of fruit and vegetables is a notable result worthy of further investigation. The intervention also led to significant changes in knowledge, attitudes and self-efficacy; a decrease in barriers to fruit and vegetable consumption; and a positive shift along the stage-of-change continuum in intervention participants. The changes were more pronounced for vegetables than for fruit, which is consistent with the emphasis placed on vegetables during the intervention. These results are consistent with the adopted theoretical underpinnings and provide a possible explanation for the mechanism for change.

\section{Strengths and limitations}

The strengths of the present study include its design as a randomised controlled trial and the communitybased nature of the intervention making participation easy. The formative evaluation and the use of theoretical models to inform the strategy are also strengths of the intervention.
A limitation of the study is the limited time frame for follow-up. In addition, reliance on self-reported data may result in response bias. Seasonal effects are potentially a limitation of fruit and vegetable interventions ${ }^{(33,35)}$; however, as data from both study groups were collected concurrently, the randomised design should have distributed any potential bias due to seasonality evenly across the intervention and control groups.

An additional limitation in terms of assessing the feasibility of using peer educators to deliver the intervention was the use of dietetics students to deliver some sessions. While this group had some of the attributes of peer educators, they did not satisfy a strict definition of peer educators.

\section{Conclusions}

The Fruit \& Veg \$ense programme has demonstrated positive short-term changes in consumption, providing promising evidence of the efficacy of such an approach. Further research is needed to test its longer-term impact and to establish the effectiveness following broad community roll out.

\section{Acknowledgements}

The Australian Government Department of Health and Ageing provided funding for project costs but had no influence on the design, analysis or reporting. The authors have no conflicts of interest to declare. C.G. developed the methodology and the questionnaire and was responsible for data analysis and writing the manuscript. K.C. provided advice on the methodology and implementation of the trial and assisted in writing the manuscript. K.G. and T.W coordinated the implementation of the trial and assisted in writing the manuscript. E.J. provided advice on the methodology and statistical analysis and assisted in writing the manuscript. The authors thank Heidi Cobb for providing voluntary administration support to the trial and Christophe Lecathelinais for assistance with statistical advice; and are grateful to the peer educators who volunteered their time to deliver the Fruit \& Veg \$ense sessions.

\section{References}

1. Begg S, Vos T, Barker B et al. (2007) The Burden of Disease and Injury in Australia 2003. Canberra: AIHW.

2. Lichtenstein AH, Appel LJ, Brands M et al. (2006) Diet and lifestyle recommendations revision 2006: a scientific statement from the American Heart Association Nutrition Committee. Circulation 114, 82-96.

3. National Health and Medical Research Council (2003) Dietary Guidelines for Australian Adults. http:// www.nhmrc.gov.au/publications/synopses/_files/n33.pdf (accessed October 2011). 
4. World Health Organization (2003) Diet, Nutrition and the Prevention of Chronic Diseases. Report of a Joint WHO/FAO Expert Consultation. WHO Technical Report Series no. 916. Geneva: WHO.

5. Marks GC, Pang G, Coyne T et al. (2001) Cancer Costs in Australia - The Potential Impact of Dietary Change. Canberra: Australian Food and Nutrition Monitoring Unit.

6. Khaw KT, Bingham S, Welch A et al. (2001) Relation between plasma ascorbic acid and mortality in men and women in EPIC-Norfolk prospective study: a prospective population study. European Prospective Investigation into Cancer and Nutrition. Lancet 357, 657-663.

7. He FJ, Nowson CA, Lucas M et al. (2007) Increased consumption of fruit and vegetables is related to a reduced risk of coronary heart disease: meta-analysis of cohort studies. J Hum Hypertens 21, 717-728.

8. Australian Bureau of Statistics \& Commonwealth Department of Health and Family Services (1998) National Nutrition Survey: Foods Eaten. Catalogue no. 4804.0 [Australian Bureau of Statistics, editor]. Canberra: ABS.

9. Centre for Epidemiology and Research (2010) 2009 Summary Report on Adult Health from the New South Wales Population Health Survey. Sydney: NSW Department of Health.

10. Australian Department of Health and Ageing (2009) Go for 2E5. Canberra: Australian Department of Health and Ageing.

11. Wardle J, Cooke LJ, Gibson EL et al. (2003) Increasing children's acceptance of vegetables; a randomized trial of parent-led exposure. Appetite 40, 155-162.

12. Contento IR (2008) Nutrition education: linking research, theory, and practice. Asia Pac J Clin Nutr 17, Suppl. 1, 176-179.

13. Ciliska D, Miles E, O'Brien MA et al. (2000) Effectiveness of community-based interventions to increase fruit and vegetable consumption. J Nutr Educ 32, 341-353.

14. Pomerleau J, Lock K, Knai C et al. (2005) Interventions designed to increase adult fruit and vegetable intake can be effective: a systematic review of the literature. J Nutr $\mathbf{1 3 5}$, 2486-2495.

15. Campbell MK, Demark-Wahnefried W, Symons M et al. (1999) Fruit and vegetable consumption and prevention of cancer: the Black Churches United for Better Health project. Am J Public Health 89, 1390-1396.

16. Langenberg P, Ballesteros M, Feldman R et al. (2000) Psychosocial factors and intervention-associated changes in those factors as correlates of change in fruit and vegetable consumption in the Maryland WIC 5 A Day Promotion Program. Ann Behav Med 22, 307-315.

17. Foley RM \& Pollard CM (1998) Food Cent\$ - implementing and evaluating a nutrition education project focusing on value for money. Aust N Z J Public Health 22, 494-501.

18. Henrikson D, James R, Ash S et al. (1990) Using volunteers to implement nutrition education programs: lessons from the North Coast experiment. Aust J Nutr Diet 47, 107-111.

19. Eng E (1993) The Save our Sisters Project. A social network strategy for reaching rural black women. Cancer $\mathbf{7 2}$, 3 Suppl., 1071-1077.
20. Buller DB, Morrill C, Taren D et al. (1999) Randomized trial testing the effect of peer education at increasing fruit and vegetable intake. J Natl Cancer Inst 91, 1491-1500.

21. Van Duyn MA, Kristal AR, Dodd K et al. (2001) Association of awareness, intrapersonal and interpersonal factors, and stage of dietary change with fruit and vegetable consumption: a national survey. Am J Health Promot 16, 69-78.

22. Bandura A (1986) Social Foundations of Thought and Action: A Social Cognitive Theory. Englewood Cliffs, NJ: Prentice-Hall.

23. Green LW \& Kreuter MW (1991) Health Promotion Planning: An Educational and Environmental Approach, 2nd ed. Mountain View, CA: Mayfield Publishing Co.

24. Prochaska JO \& DiClemente CC (1983) Stages and processes of self-change of smoking: toward an integrative model of change. J Consult Clin Psychol 51, 390-395.

25. Ma J, Betts NM, Horacek T et al. (2003) Assessing stages of change for fruit and vegetable intake in young adults: a combination of traditional staging algorithms and foodfrequency questionnaires. Health Educ Res 18, 224-236.

26. Russell SS (2006) An overview of adult-learning processes. Urol Nurs 26, 349-352, 370.

27. Glasson C, Chapman K \& James E (2011) Fruit and vegetables should be targeted separately in health promotion programmes: differences in consumption levels, barriers, knowledge and stages of readiness for change. Public Health Nutr 14, 694-701.

28. Giles GG \& Ireland PD (1996) Dietary Questionnaire for Epidemiological Studies (Version 2). Melbourne: Cancer Council Victoria.

29. Xinying PX, Noakes M \& Keogh J (2004) Can a food frequency questionnaire be used to capture dietary intake data in a 4 week clinical intervention trial? Asia Pac J Clin Nutr 13, 318-323.

30. Department of Health and Ageing (1998) Australian Guide to Healthy Eating. Canberra: Department of Health and Ageing; available at http://www.health.gov.au/ internet/main/publishing.nsf/Content/FD699468D52A5A2 ECA256F19000406D6/\$File/fdeduc.pdf

31. The Cancer Council NSW (2007) NSW Healthy Food Basket Cost, Availability and Quality Survey. Sydney: The Cancer Council NSW; available at http://www.cancercouncil.com.au/ foodbasket

32. Havas S, Treiman K, Langenberg P et al. (1998) Factors associated with fruit and vegetable consumption among women participating in WIC. J Am Diet Assoc 98, 1141-1147.

33. Havas S, Anliker J, Greenberg D et al. (2003) Final results of the Maryland WIC Food for Life Program. Prev Med 37, 406-416.

34. Haire-Joshu D, Brownson RC, Nanney MS et al. (2003) Improving dietary behavior in African Americans: the Parents As Teachers High 5, Low Fat Program. Prev Med 36, 684-691.

35. Ni Mhurchu C, Blakely T, Wall J et al. (2007) Strategies to promote healthier food purchases: a pilot supermarket intervention study. Public Health Nutr 10, 608-615. 